\title{
Synthesis and characterization of Ruddlesden-Popper (RP) type phase $\mathrm{LaSr}_{2} \mathrm{MnCrO}_{7}$
}

\author{
DEVINDER SINGH* and RAJINDER SINGH \\ Department of Chemistry, University of Jammu, Jammu 180006 \\ e-mail: drdssambyal@rediffmail.com
}

MS received 5 February 2010; revised 22 April 2010; accepted 4 May 2010

\begin{abstract}
New Ruddlesden-Popper (RP) type phase $\mathrm{LaSr}_{2} \mathrm{MnCrO}_{7}$ has been synthesized by ceramic method. Rietveld profile analysis shows that the phase crystallizes with tetragonal unit cell in the space group I4/mmm. The electrical resistivity of the phase has been measured in the temperature range of 10-300 K using Leybold closed cycle helium cryostat. The phase shows insulator-metal (I-M) transition at low temperature, the phenomenon often associated with giant magnetoresistance. 3D variable range hopping governs the electrical conduction in the insulator region above the I-M transition temperature. Magnetic susceptibility of the phase has been measured in the temperature range of 100-300 K. Magnetic studies suggest that the phase is ferromagnetic.
\end{abstract}

Keywords. $\quad \mathrm{LaSr}_{2} \mathrm{MnCrO}_{7}$; structure; rietveld $\mathrm{XRD}$ analysis; magnetoresistance; ferromagnetic.

\section{Introduction}

The Ruddlesden-Popper (RP) type phases of general formula $\mathrm{A}_{n+1} \mathrm{~B}_{n} \mathrm{O}_{3 n+1}$ or $\mathrm{AO}\left(\mathrm{ABO}_{3}\right)_{n}$ (where $\mathrm{A}$ is rare earth/alkaline earth ion, $\mathrm{B}$ is a transition metal ion), generally crystallize with tetragonal or orthorhombic unit cell in the space group $14 / \mathrm{mmm}$ or $\mathrm{Fmmm}^{1-7}$ The crystal structure of these phases can be described by the stacking of finite $n$ layers of perovskites $\mathrm{ABO}_{3}$ between rock salt $\mathrm{AO}$ layers along the crystallographic $c$ direction. ${ }^{8}$ The first member of the RP family, $n=1$, is $\mathrm{A}_{2} \mathrm{BO}_{4}$, which adopts the $\mathrm{K}_{2} \mathrm{NiF}_{4}$-type structure with only one layer of cornersharing $\mathrm{BO}_{6}$ octahedra along the $c$ direction. In the second member of the RP family, $\mathrm{A}_{3} \mathrm{~B}_{2} \mathrm{O}_{7}$, two infinite $\mathrm{BO}_{6}$ sheets are connected in the $c$ direction between the rock-salt layers. The three $\mathrm{ABO}_{3}$ perovskite layers with corner-sharing $\mathrm{BO}_{6}$ octahedra along $c$ direction are separated by $\mathrm{AO}$ rock-salt layers in the third member of the RP family, $\mathrm{A}_{4} \mathrm{~B}_{3} \mathrm{O}_{10}$. The $n=1$ phases with $\mathrm{K}_{2} \mathrm{NiF}_{4}$ type structure, possess $2 \mathrm{D}$ character. Increase in $n$ is expected to strengthen $\mathrm{B}-\mathrm{O}-\mathrm{B}$ interactions along the crystallographic $c$-axis resulting in increased 3D character in higher members of the family. Physical properties of such phases are governed by valence state of ions, width of $n$ perovskite slabs and oxygen content. These phases

\footnotetext{
*For correspondence
}

are generally electrical insulators and antiferromagnetic in nature, although some exceptions from this general trend has also been observed. ${ }^{9-11}$ The substitution at $\mathrm{A}$ and $\mathrm{B}$ sites show many interesting physical properties. Some layered manganites with RPtype structure $(n=2)$ are known to exhibit insulatormetal (I-M) transition in their electric transport behaviour and ferromagnetic transformation at low temperatures, the phenomenon associated with giant magnetoresistance. ${ }^{12,13}$

Some $\mathrm{Cr}$ doped $\mathrm{LaSr}_{2} \mathrm{Mn}_{2} \mathrm{O}_{7}$ manganites with layered structure are reported in the literature. ${ }^{14,15}$ The increase of resistivity and slight change in magnetization in these phases is related to the combined effect of the partial destruction of the $\mathrm{Mn}-\mathrm{O}-\mathrm{Mn}$ interaction network within the ferromagnetic (FM) layers of an A-type antiferromagnet and the appearance of $\mathrm{Cr}^{3+}-\mathrm{O}-\mathrm{Mn}^{3+} \mathrm{FM}$ interaction. Additionally, the introduction of the random Coulomb potential caused by the substitution of $\mathrm{Cr}^{3+}$ for $\mathrm{Mn}^{3+}$ is also a source of increased resistivity. The electrical conduction in such phases is governed by threedimensional variable range-hopping (VRH) mechanism. In this paper, the new RP-type phase $\mathrm{LaSr}_{2} \mathrm{MnCrO}_{7}$ has been synthesized and its crystal structure has been determined by Rietveld profile analysis of X-ray diffraction data. The electrical resistivity and magnetic susceptibility has been studied as functions of temperature. 


\section{Experimental}

The phase $\mathrm{LaSr}_{2} \mathrm{MnCrO}_{7}$ was prepared by the standard ceramic method by heating the stoichiometric amounts of $\mathrm{La}_{2} \mathrm{O}_{3}, \mathrm{SrCO}_{3}, \mathrm{Mn}_{2} \mathrm{O}_{3}$ and $\mathrm{Cr}_{2} \mathrm{O}_{3}$ (purity $99.9 \%$ ). A $5 \%$ of $\mathrm{SrCO}_{3}$ was added in excess to compensate for its loss at high temperature. Prior to use, $\mathrm{La}_{2} \mathrm{O}_{3}$ was heated at $950^{\circ} \mathrm{C}$ to remove absorbed moisture and $\mathrm{CO}_{2}$. Before heating, the reactants were mixed and homogenized by grinding in cyclohexane and pressed into pellets. The pellets were heat-treated at $1543 \mathrm{~K}$ in static air atmosphere for about $90 \mathrm{~h}$ with a number of intermediate grindings and pelletizings. The black coloured products were finally pulverized and analysed by usual chemical methods for the constituent cations.

Room temperature powder X-ray diffraction data of the phase was recorded on Phillips diffractometer type PW 1820 using $\mathrm{CuK}_{\alpha}$ radiations in $2 \theta$ range of $10-70^{\circ}$. The data were analysed with the Rietveld analysis programme DBWS-9807 for the structure determination. ${ }^{16}$

The electrical resistivity of the pellet of the phase sintered at $1450 \mathrm{~K}$ was recorded by four probe method in the temperature range of $10-300 \mathrm{~K}$ using Leybold closed cycle helium cryostat. Thin copper wires were attached to the surface of pellet with Epotek silver epoxy E-4110 for the purpose of electrodes. The magnetic susceptibility of the polycrystalline phase was measured by Faraday technique in the temperature of range $100-300 \mathrm{~K}$ using $\mathrm{Hg}\left[\mathrm{Co}(\mathrm{SCN})_{4}\right]$ as calibrant. All magnetic susceptibility values were corrected for diamagnetism of the constituent ions.

\section{Results and discussion}

The X-ray diffraction data of $\mathrm{LaSr}_{2} \mathrm{MnCrO}_{7}$ could be indexed with tetragonal unit cell in the space group $I 4 / \mathrm{mmm}$. No trace of any extra peaks due to constituent oxides or $n=1$ or $n=3$ phases was found, suggesting the formation of single phase compound. The Rietveld analysis of the X-ray diffraction data of the phase was done starting with the model of the well-known RP-type $n=2$ phase, $\mathrm{Sr}_{3} \mathrm{Ti}_{2} \mathrm{O}_{7}{ }^{8}$ The structure was refined in the space group $14 / \mathrm{mmm}$, assuming a pseudo-Voight $(\mathrm{pV})$ peak shape function. The Rietveld refinement of the powder diffraction data is shown in figure 1 . The refinement values, structural parameters and $R$-factors along with the estimated standard deviation (ESD) of the last signi- ficant number for the phase are given in the table 1. The $S$ (goodness of fit) value calculated from $R_{\mathrm{wb}} / R_{\text {exp }}$ comes to be $1 \cdot 28$. The selected bond lengths and bond angles, calculated from the structural parameters of the phase, are also tabulated in the table 1. The results suggest that the occupancy of oxygen at the site $(2 \mathrm{a} ; 000)$ is 0.95 , which shows that the phase is oxygen deficient with composition $\mathrm{LaSr}_{2} \mathrm{MnCrO}_{7-\delta}$. It may be noted that of the three oxygen positions, the $\mathrm{O}(1)$ site is of course, the preferred one for the oxygen loss in this type of phases. ${ }^{17}$ The decrease in oxygen content suggests that manganese is present in mixed valence state of $\mathrm{Mn}^{3+} / \mathrm{Mn}^{4+}$. The temperature factor (B) has comparatively large values for various ions, especially the oxygen ions, signifying displacement of the ions from their ideal positions. A look at the bond angles and the bond lengths for the phase shows that there is significant distortion in the cell structure.

The goodness of fit, $\mathrm{S}$, value 1.28 for the phase is reasonable for assigning the structure to the phase on the basis of the Rietveld analysis. The results of $\mathrm{X}$-ray diffraction studies show that the phase with composition $\mathrm{LaSr}_{2} \mathrm{MnCrO}_{7-\delta}$ has been formed with the RP-type $(n=2)$ structure, where unit cell takes up distorted structure due to John-Teller effect, which is caused by part presence of $\mathrm{Mn}^{3+}$ ion. Representative unit cell structure of $\mathrm{LaSr}_{2} \mathrm{MnCrO}_{7}$ is given (see figure 4).

The temperature dependence of resistivity of the phase is shown in figure 2. The plot shows that the temperature co-efficient of resistivity is negative, above $48 \mathrm{~K}$ suggesting that the material is an insulator above this temperature. The linearity of $\log \rho$ versus $T^{-1 / 4}$ plot (figure 2 ) in the temperature region $(70-300 \mathrm{~K})$ shows that the electronic conduction in the insulator region occurs by a $3 \mathrm{D}$ variable range hopping mechanism. The insulator behaviour is attributed to the superexchange coupling of electrons. As the temperature falls below $48 \mathrm{~K}$, the temperature coefficient of resistivity abruptly becomes positive and the phase becomes metallic in nature. It is reported in the literature that mixed valence layered manganites exhibit I-M transition at low temperatures and the $\mathrm{Mn}^{3+} / \mathrm{Mn}^{4+}$ mixed valence state in these manganites creates mobile charge carriers which is for I-M transition. ${ }^{12,13,18,19}$. The I-M transition is due to transfer of $e_{g}$ electron between $\mathrm{Mn}^{3+}$ and $\mathrm{Mn}^{4+}$ oxidation states by double exchange mechanism. The ionic states $\left(\mathrm{Mn}^{3+} / \mathrm{Mn}^{4+}\right)$ fluctuates because of electron transfer between them. 


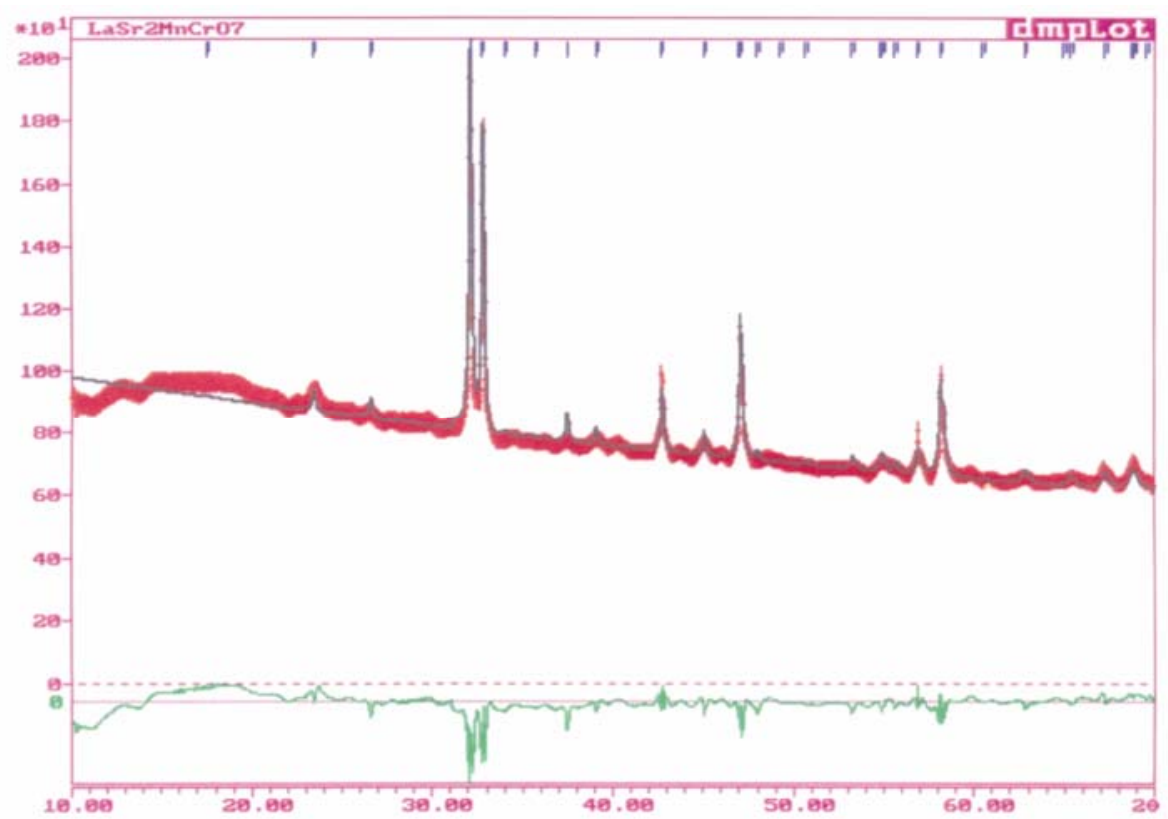

Figure 1. Rietveld plots showing the observed, calculated and the difference pattern for $\mathrm{LaSr}_{2} \mathrm{MnCrO}_{7}$.

Table 1. Structural parameters of $\mathrm{LaSr}_{2} \mathrm{MnCrO}_{7}$.

\begin{tabular}{|c|c|c|c|c|c|c|}
\hline \multicolumn{7}{|c|}{ Positional co-ordinates of $\mathrm{La}, \mathrm{Sr}, \mathrm{Mn}, \mathrm{Cr}$ and $\mathrm{O}$} \\
\hline Atom & Site & $x$ & $y$ & $z$ & $B\left(\AA^{2}\right)$ & Occupancy \\
\hline $\mathrm{La} / \mathrm{Sr}(1)$ & $2 b$ & $0 \cdot 0$ & $0 \cdot 0$ & 0.5 & $0.98(2)$ & 1 \\
\hline $\mathrm{La} / \mathrm{Sr}(2)$ & $4 \mathrm{e}$ & $0 \cdot 0$ & $0 \cdot 0$ & $0 \cdot 3116(6)$ & $0.92(5)$ & 1 \\
\hline $\mathrm{Mn} / \mathrm{Cr}$ & $4 \mathrm{e}$ & $0 \cdot 0$ & $0 \cdot 0$ & $0.0910(5)$ & $1 \cdot 03(4)$ & 1 \\
\hline $\mathrm{O}(1)$ & $2 \mathrm{a}$ & $0 \cdot 0$ & $0 \cdot 0$ & $0 \cdot 0$ & $1 \cdot 36(10)$ & $0.95(4)$ \\
\hline $\mathrm{O}(2)$ & $4 \mathrm{e}$ & $0 \cdot 0$ & $0 \cdot 0$ & $0 \cdot 1749(9)$ & $1 \cdot 32(7)$ & 1 \\
\hline $\mathrm{O}(3)$ & $8 \mathrm{~g}$ & $0 \cdot 0$ & $0 \cdot 5$ & $0 \cdot 1083(7)$ & $1 \cdot 12(5)$ & 1 \\
\hline \multicolumn{7}{|c|}{ Selected bond lengths $(\AA)$} \\
\hline \multicolumn{2}{|c|}{$\mathrm{La} / \operatorname{Sr}(1)-\operatorname{Sr}(2)$} & \multicolumn{2}{|c|}{$3.781(0 \cdot 004)$} & & & \\
\hline \multicolumn{2}{|c|}{$\mathrm{La} / \mathrm{Sr}(2)-\mathrm{O}(2)$} & \multicolumn{2}{|c|}{$2.743(0.020)$} & & & \\
\hline \multirow{2}{*}{\multicolumn{2}{|c|}{$\mathrm{Mn} / \mathrm{Cr}-\mathrm{O}(1)$}} & \multicolumn{2}{|c|}{$1.826(0.008)$} & & & \\
\hline & & \multicolumn{2}{|c|}{$1.684(0.004)$} & & & \\
\hline \multicolumn{2}{|c|}{$\mathrm{Mn} / \mathrm{Cr}-\mathrm{O}(3)$} & 1.958 & & & & \\
\hline \multicolumn{7}{|c|}{ Selected bond angles $\left({ }^{\circ}\right)$} \\
\hline \multicolumn{2}{|c|}{$\mathrm{La} / \mathrm{Sr}(1)-\mathrm{La} / \mathrm{Sr}(2)-\mathrm{O}(2)$} & \multicolumn{2}{|c|}{$180 \cdot 00(0 \cdot 26)$} & & & \\
\hline \multicolumn{2}{|c|}{$\begin{array}{l}\mathrm{O}(2)-\mathrm{Mn} / \mathrm{Cr}-\mathrm{O}(3) \\
\mathrm{O}(1)-\mathrm{Mn} / \mathrm{Cr}-\mathrm{O}(2)\end{array}$} & \multicolumn{2}{|c|}{$79.78(0.62)$} & & & \\
\hline \multicolumn{2}{|c|}{$\mathrm{O}(1)-\mathrm{Mn} / \mathrm{Cr}-\mathrm{O}(2)$} & \multicolumn{2}{|c|}{$180.00(0.50)$} & & & \\
\hline \multicolumn{2}{|c|}{$\mathrm{O}(1)-\mathrm{Mn} / \mathrm{Cr}-\mathrm{O}(3)$} & \multicolumn{2}{|c|}{$100 \cdot 21(0.49)$} & & & \\
\hline \multicolumn{2}{|c|}{$\mathrm{La} / \mathrm{Sr}(2)-\mathrm{O}(2)-\mathrm{Mn} / \mathrm{Cr}$} & \multicolumn{2}{|c|}{$180.00(0.66)$} & & & \\
\hline
\end{tabular}

Lattice constants: $a=3.8533$ (21) $\AA, c=20.0710$ (36) $\AA$, Cell volume $=298.01 \AA^{3}, R_{\mathrm{wp}}=$ $4.53 \%, R_{\exp }=3.54 \%$ and $\mathrm{S}$ (goodness of fit) $=1.28$.

Inverse molar magnetic susceptibility $\chi_{\mathrm{M}}^{-1}$ versus temperature plot for the phase is given in figure 3. The curie temperature $(\theta)$ from the high temperature region is positive suggesting that the phase is ferro- magnetic. The variation of magnetization with temperature (figure 3) also shows ferromagnetic behaviour with temperature of ferromagnetic ordering of $134 \mathrm{~K}$. The ferromagnetism arises due to $\mathrm{Mn}^{3+}-\mathrm{O}_{-}$ 


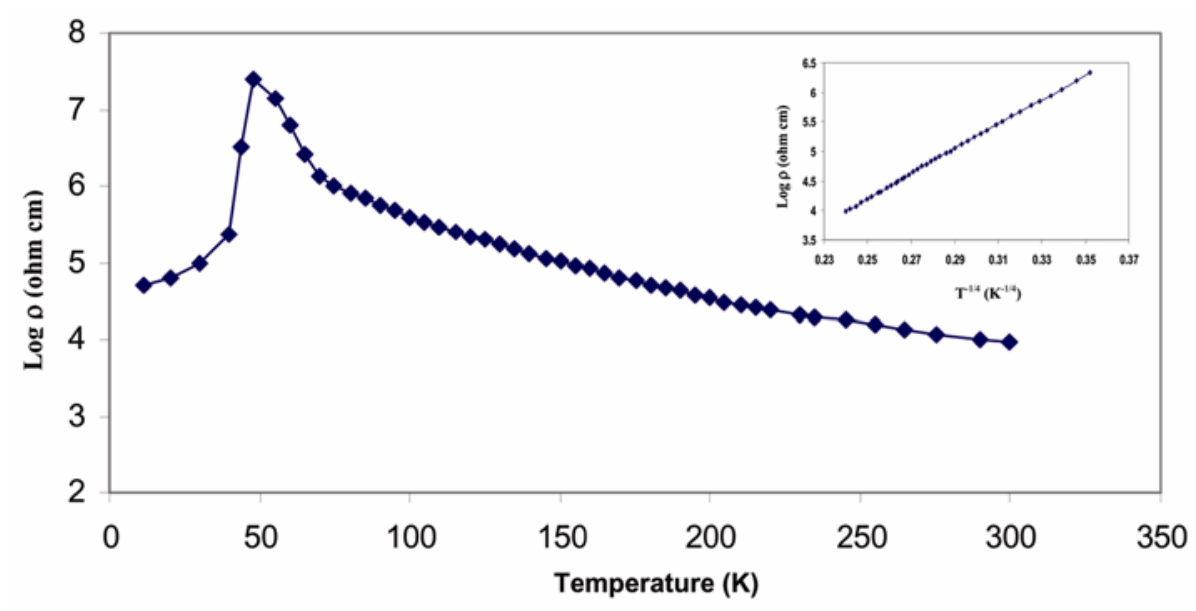

Figure 2. Plot of $\log \rho$ versus temperature $(\mathrm{K})$ of $\mathrm{LaSr}_{2} \mathrm{MnCrO}_{7}$. Inset shows the $\log \rho$ versus $T^{-1 / 4}$ plot of $\mathrm{LaSr}_{2} \mathrm{MnCrO}_{7}$.

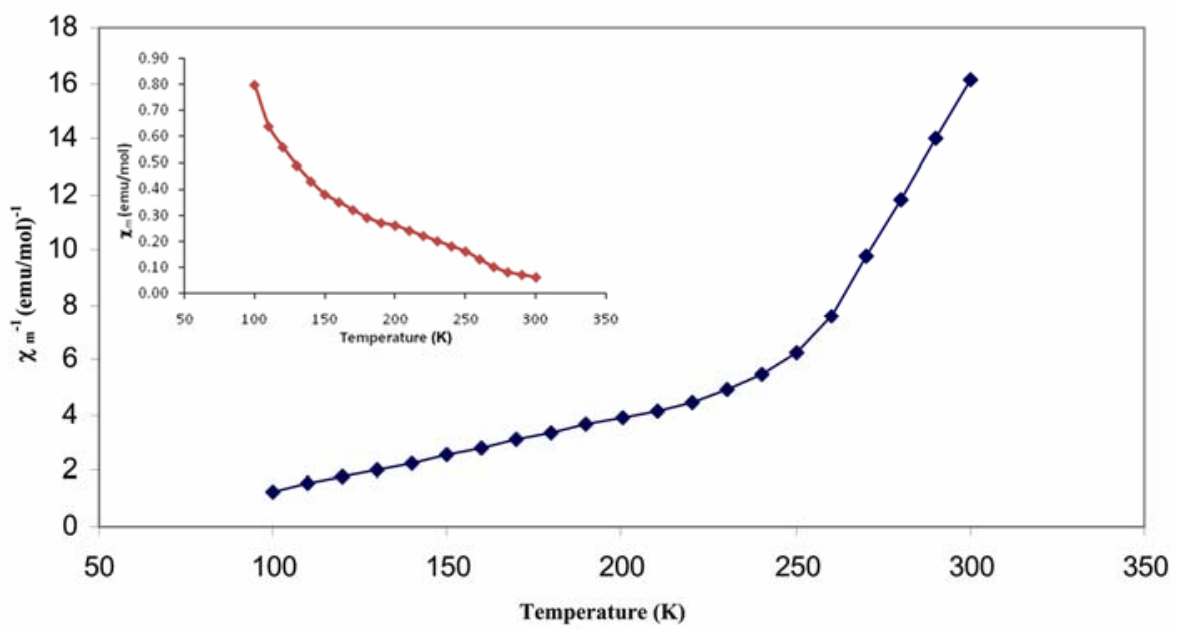

Figure 3. Plot of inverse molar susceptibility $\left(\chi_{m}^{-1}\right)$ versus temperature $(\mathrm{K})$ of $\mathrm{LaSr}_{2} \mathrm{MnCrO}_{7}$. Inset shows the magnetization versus temperature $(\mathrm{K})$ plot of $\mathrm{LaSr}_{2} \mathrm{MnCrO}_{7}$.

$\mathrm{Mn}^{4+}$ interactions in the $a b$ plane. In addition, we note that the $\mathrm{Cr}^{3+}$ ion has the same electronic configuration $\left(t_{2 \mathrm{~g}}{ }^{3} e_{\mathrm{g}}{ }^{0}\right)$ as the $\mathrm{Mn}^{4+}$ ion when the $\mathrm{Cr}$ ions enter into the $\mathrm{Mn}$ site in the form of $\mathrm{Cr}^{3+}$ ions. Therefore, there may exist a FM interactions between $\mathrm{Cr}^{3+}$ and $\mathrm{Mn}^{3+}$ ions just as between $\mathrm{Mn}^{4+}$ and $\mathrm{Mn}^{3+}$ ions. This has been proved by some experimental results. ${ }^{20}$ The effective magnetic moment $\left(\mu_{\mathrm{eff}}\right)$ has been calculated from the high temperature region $(250-300 \mathrm{~K})$ and comes to be $6.03 \mathrm{~B} . \mathrm{M}$. The contribution of manganese ion $\left(\mu_{\mathrm{Mn}}\right)$ to the magnetic moment has been calculated from the effective magnetic moment $\left(\mu_{\mathrm{eff}}\right)$ and theoretical magnetic moment of $\mathrm{Cr}$ ion from the relation ${ }^{21}$

$$
\mu_{\mathrm{eff}}^{2}=n_{1} \mu_{\mathrm{Cr}^{3+}}^{2}+n_{2} \mu_{\mathrm{Mn}^{4+}}^{2},
$$

where $n_{1}$ and $n_{2}$ are the number of $\mathrm{Cr}$ and $\mathrm{Mn}$ ions in the phase.

$\mu_{\mathrm{Cr}^{3+}}$ is the theoretical magnetic moment of the $\mathrm{Cr}$ ion, assuming it to be in the high spin +3 oxidation state $\left(t_{2 \mathrm{~g}}{ }^{3} e_{\mathrm{g}}{ }^{0}\right)$. For $\mu_{\mathrm{Mn}}$, we obtain the value $4.62 \mathrm{~B}$. $\mathrm{M}$ for the given phase. This value is higher than the theoretical magnetic moment of high spin $\mathrm{Mn}^{4+}$ ion $(3.87 \mathrm{BM})$ which suggests that the manganese ion is partly present in +3 oxidation state. The results show that the $\mathrm{Mn}$ is in the mixed valence state $\left(\mathrm{Mn}^{3+} / \mathrm{Mn}^{4+}\right)$, the condition essential for the I-M transition. 


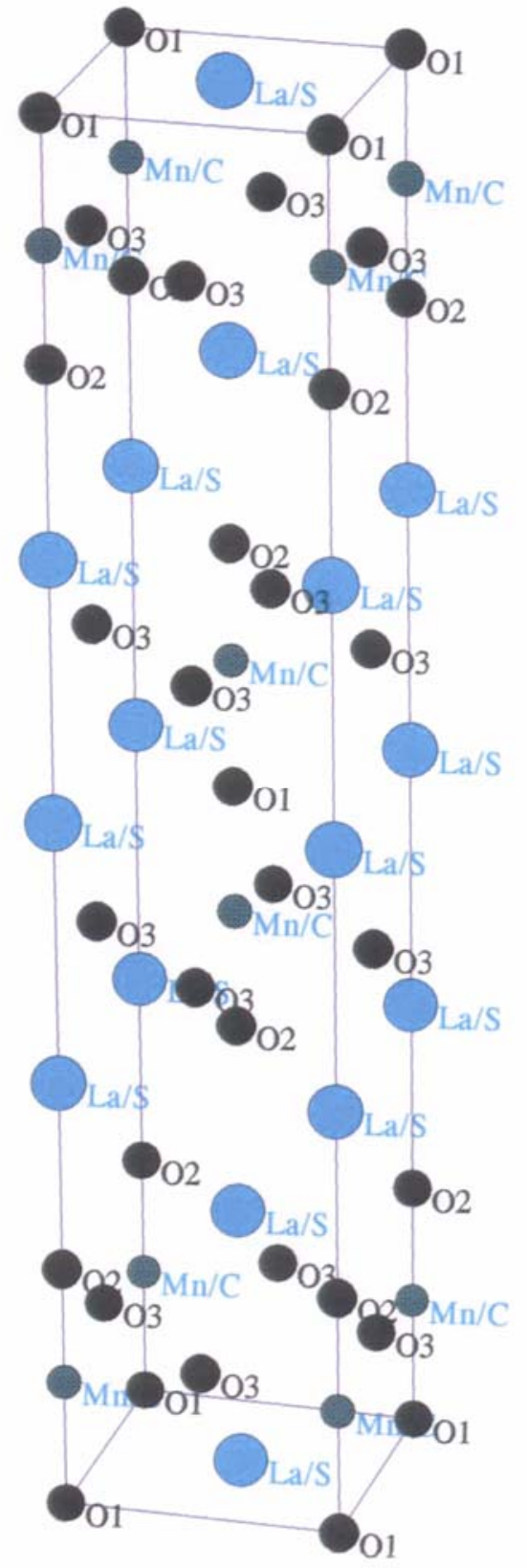

Figure 4. Unit cell structure of $\mathrm{LaSr}_{2} \mathrm{MnCrO}_{7}$.

\section{Conclusion}

A new RP-type phase of composition $\mathrm{LaSr}_{2} \mathrm{MnCrO}_{7}$ has been synthesized by standard ceramic method. Its structure has been determined by Rietveld analysis of XRD data. The results show that the phase crystallize in the $I 4 / \mathrm{mmm}$ space group with tetragonal unit cell. The electrical resistivity studies show that the material is insulator in the temperature region of $48-300 \mathrm{~K}$ and conduction occurs by a variable range hopping mechanism. The phase undergoes $\mathrm{I}-\mathrm{M}$ transition around $48 \mathrm{~K}$ and this is attributed to the mixed valence $\mathrm{Mn}^{3+} / \mathrm{Mn}^{4+}$ state. The magnetic studies suggest that the phase is ferromagnetic and manganese ion in the phase is present in mixed valence state $\left(\mathrm{Mn}^{3+} / \mathrm{Mn}^{4+}\right)$.

\section{References}

1. Liang Z, Tang K, Shao Q, Li G., Zeng S and Zeng H 2008 J. Solid State Chem. 181964

2. Bendersky L A, Greenblatt M and Chen R 2003 J. Solid State Chem. 174418

3. Zhang Z, Greenblatt M and Goodenough J B 1994 J. Solid State Chem. 108402

4. Sreedhar K, McElfresh M, Perry D, Kim D, Metcalf P and Honig J M 1994 J. Solid State Chem. 110 208

5. Rao C N R, Ganguly P, Singh K K and Mohan Ram R A 1988 J. Solid State Chem. 7214

6. Sharma I B, Singh D and Magotra S K 1998 J. Alloys Compd. 26913

7. Sharma I B and Singh D 1998 Bull. Mater. Sci. 21 363

8. Ruddlesden S N and Popper P 1958 Acta Crystallogr. 1154

9. Battle P D, Bollen S K and Powell A V 1992 J. Solid State Chem. 99267

10. Attfield M P, Battle P D, Bollen S K, Kim S H, Powell A V and Worlman M J 1992 J. Solid State Chem. 96 344

11. Lee J Y, Swinnea J S, Steinfink H, Reiff W M, Pei S and Jorgensen J D 1993 J. Solid State Chem. 1031

12. Mahesh R, Mahendiran R, Raychaudhuri A K and Rao C N R 1996 J. Solid State Chem. 122448

13. Briceno G. Chang H, Sun X, Schultz P G and Xiang X D 1995 Science 270273

14. Zhang R L, Zhao B C, Song W H, Ma Y Q, Yang J, Sheng Z G and Dai J M 2004 J. Appl. Phys. 96 4965

15. Ang R, Zhang R L, Zhao B C, Zhu X B, Song W H and Sun Y P 2006 Solid State Commun. 137492

16. Young R A, Larson A C, Paiva C O Santos 1998 DBWS-9807 Program for Rietveld Analysis, School of Physics, Georgia Institute of Technology, Atlants

17. Dann S E, Weller M T and Curie D B 1992 J. Solid State Chem. 97179

18. Raveau B, Maignan A and Caignaert V 1995 J. Solid State Chem. 117424

19. Von Helmolt R, Wecker J, Hotzapfel B, Schultz L and Samwer K 1993 Phys. Rev. Lett. 712331

20. Maignan A, Martin C, Damay F, Hervieu M and Raveau B 1998 J. Magn. Magn. Mater. 188185

21. Subramanian M A, Toradi C C, Johnson D C, Pannetier J and Sleight A W 1998 J. Solid State Chem. 72 24 